\title{
Prognostic significance of pre-treatment serum Cyfra21-1 as a tumor marker in patients with oropharyngeal squamous cell carcinoma treated with concurrent chemoradiotherapy
}

\author{
Liang Li ${ }^{1,2 \#}$, Guangping Liu ${ }^{2 \#}$, Kai Jin ${ }^{1,3 \#}$, Honglue Lu ${ }^{1}$, Xiang Zhai ${ }^{1}$, Mengqian Zhou ${ }^{1}$, Kai Yue ${ }^{1}$, \\ Yuansheng Duan ${ }^{1}$, Yansheng $\mathrm{Wu}^{1}$, Xudong Wang ${ }^{1}$ \\ ${ }^{1}$ Department of Maxillofacial \& E.N.T Oncology, Tianjin Medical University Cancer Institute and Hospital, National Clinical Research Center \\ for Cancer, Key Laboratory of Cancer Prevention and Therapy, Tianjin's Clinical Research Center for Cancer, Tianjin, China; ${ }^{2}$ Departmentof \\ Otolaryngology, Tianjin Children's Hospital, Tianjin University Children's Hospital, Tianjin, China; ${ }^{3}$ Department of Thyroid Neoplasms Surgery, \\ Inner Mongolia People's Hospital, Hohhot, China \\ Contributions: (I) Conception and design: L Li; (II) Administrative support: X Wang; (III) Provision of study materials or patients: K Jin; (IV) \\ Collection and assembly of data: G Liu; (V) Data analysis and interpretation: L Li; (VI) Manuscript writing: All authors; (VII) Final approval of \\ manuscript: All authors. \\ "These authors contribute equally to this work. \\ Correspondence to: Prof. Xudong Wang; Yansheng Wu. Department of Maxillofacial \& E.N.T Oncology, Tianjin Medical University Cancer Institute \\ and Hospital, National Clinical Research Center for Cancer, Key Laboratory of Cancer Prevention and Therapy, Tianjin's Clinical Research Center \\ for Cancer, Tianjin 300060, China. Email: WXD.1133@163.com; yansheng1981@163.com.
}

Background: Oropharyngeal squamous cell carcinoma (OPSCC) is a kind of squamous cell carcinoma of head and neck, and its incidence is on the rise in recent years. A variety of prognostic markers for OPSCC have been reported in many studies, but they are expensive or difficult to obtain. So, we retrospectively studied the prognostic significance of cytokeratin 19 soluble fragment (Cyfra21-1) in patients with OPSCC, in order to provide theoretical basis for accurate prognosis assessment.

Methods: A retrospective analysis of the clinicopathological data of 85 OPSCC patients with concurrent radiotherapy and chemotherapy (CRT) admitted from January 2010 to June 2017. Serum Cyfra21-1 levels were measured before treatment. Analyze the relationship between Cyfra21-1 and clinical pathological characteristics of patients. The receiver operating characteristic (ROC) curve was used to calculate the cutoff value of Cyfra21-1. The Cox proportional hazard model was used to conduct univariate and multivariate analysis of related prognostic factors, and to determine the factors related to overall survival (OS) and progression-free survival (PFS).

Results: The cutoff value for Cyfra21-1 was $2.93 \mathrm{ng} / \mathrm{mL}$. The baseline data of patients in different Cyfra21-1 groups were balanced and comparable. In the univariate and multivariate analyses, it was found that Cyfra21-1 was associated with OS and PFS. A measurement of Cyfra21-1 $\geq 2.93 \mathrm{ng} / \mathrm{mL}$ indicated poor OS $(\mathrm{P}<0.001)$ and PFS $(\mathrm{P}=0.001)$. After adjusting for age and disease stage, Cyfra21-1 can independently affect the OS (HR =3.57, 95\% CI: 1.60-7.99, $\mathrm{P}=0.002)$ and PFS (HR =2.89, 95\% CI: $1.41-5.91, \mathrm{P}=0.004)$ of patients with OPSCC treated with CRT.

Conclusions: Pre-treatment Cyfra21-1 can be used as a prognostic marker for patients with OPSCC treated with CRT, which has important clinical significance.

Keywords: Oropharyngeal squamous cell carcinoma (OPSCC); cytokeratin 19 soluble fragment (Cyfra21-1); concurrent chemoradiotherapy (CRT); prognosis; survival

Submitted Jul 31, 2020. Accepted for publication Oct 16, 2020.

doi: $10.21037 /$ atm-20-6124

View this article at: http://dx.doi.org/10.21037/atm-20-6124 


\section{Introduction}

Oropharyngeal squamous cell carcinoma (OPSCC) accounts for about $2 \%$ of malignant tumors in the whole body (1), and the overall prognosis is poor. The 5 -year overall survival (OS) rate of patients is only about $50 \%(2,3)$, among which the 5 -year survival rate of advanced stage patients is $<40 \%(1)$, while that of early stage patients can reach $>80 \%(1,4)$. Therefore, early detection and intervention is important to improve the survival rate and quality of life of patients with OPSCC $(1,5)$. OPSCC patients are usually treated according to the 8 th edition of AJCC staging, including comprehensive treatment based on surgery and CRT.

It is reported that many indicators play an important role in the diagnosis and treatment of OPSCC, including, circulating neutrophil count (CNC), p16 protein and so on. Recently, the study of serum tumor markers in the early detection of malignant tumors has attracted increased attention $(4,6)$. A serum tumor marker is a kind of abnormal substance produced by the expression of tumor related genes or the body's response to tumors during the occurrence and proliferation of malignant carcinomata (7). Cytokeratin 19 soluble fragment (Cyfra21-1) is a newly established monoclonal antibody; it is a serum cytokeratin 19 fragment, which has specific reaction with cytokeratin 19 (8). A recent meta-analysis revealed that Cyfra21-1 has a relatively high diagnostic value for detecting non-small cell lung cancer (NSCLC), especially in patients with squamous cell carcinoma (9). Recently, Many studies have explored the correlation between Cyfra21-1 and the clinical outcomes of NSCLC patients (10-12).

It has also been proven that Cyfra21-1 can independently be used as a prognostic indicator of a variety of malignant tumors. Numerous studies have shown that it has important prognostic significance for middle and advanced cancers, such as esophageal cancer, bladder cancer, epithelial ovarian cancer, and intrahepatic cholangiocarcinoma (13-16). Lei et al. found that Cyfra21-1 could be used to predict the early recurrence of OPSCC by comparing between groups, and the concentration of Cyfra21-1 was related to the clinicopathological stage of OPSCC. At present, there is no relevant literature on the application of Cyfra21-1 for survival analysis of OPSCC patients. Therefore, we performed survival analysis and multivariate regression analysis of the prognostic significance of Cyfra21-1 in patients with OPSCC treated with concurrent chemoradiotherapy (CRT), in order to provide theoretical basis for accurate prognosis assessment We present the following article in accordance with the REMARK reporting checklist (available at http://dx.doi.org/10.21037/ atm-20-6124).

\section{Methods}

\section{Patients}

The clinical data of 85 patients diagnosed as OPSCC who received CRT treatment in the Oncology radiotherapy Department of Tianjin Medical University Cancer Hospital from January 2010 to June 2017 were retrospectively analyzed. The study was approved by the ethics committee of the Tianjin Medical University Cancer Institute and Hospital (No. bc2020110). A signed written informed consent agreement was provided by all patients before participation in the study. All procedures performed in this study involving human participants were in accordance with the Declaration of Helsinki (as revised in 2013). Inclusion criteria for this study: (I) primary OPSCC as confirmed by biopsy; (II) complete clinical data; (III) Cyfra21-1 was tested during the week prior to initiation of treatment; (IV) receive CRT treatment. Exclusion criteria include: (I) combination with other systemic malignancies; (II) incomplete clinical data; (III) co-existing with other respiratory diseases.

\section{Treatment}

All patients received concurrent radiochemotherapy, in accordance with the 8 th edition of the National Comprehensive Cancer Network guidelines. The specific plan stipulates that all patients are treated with intensity modulated radiotherapy (IMRT) $1 \times /$ day and $5 \times /$ week. The prescription dose of primary tumor focus in the oropharynx is $69.96 \mathrm{~Gy} / 2.12 \mathrm{~Gy} / 33 \mathrm{f}$. The prescription dose of highrisk lymphatic drainage area is $60.06 \mathrm{~Gy} / 1.82 \mathrm{~Gy} / 33 \mathrm{f}$. The prescription dose of low-risk lymphatic drainage area is $50.96 \mathrm{~Gy} / 1.82 \mathrm{~Gy} / 28 \mathrm{f}$. All patients were treated with concurrent chemotherapy, cisplatin $40 \mathrm{mg} / \mathrm{m}^{2}$ weekly for 4 cycles.

\section{Blood tests}

Blood samples were taken from all patients who met the inclusion criteria one week prior to treatment. The patient's blood samples were kept in test tubes treated with ethylenediamine tetraacetic acid. Then, Cyfra21-1 was detected with an automatic chemiluminescence 


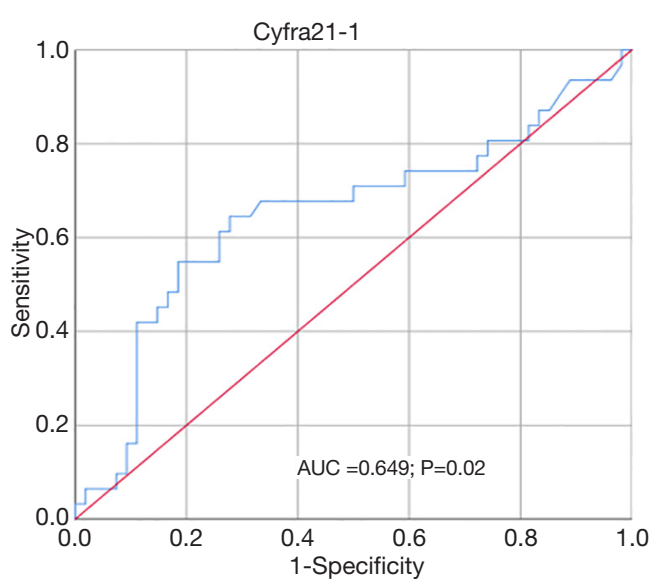

Figure 1 ROC curve for Cyfra21-1 predicting OS. Cyfra21-1, cytokeratin 19 soluble fragment; ROC, receiver operating characteristic; OS, overall survival.

immunoassay analyzer (Roche cobase801, Germany).

The quantitative patient serum and horseradish peroxide (HRP) were added to the solid phase white opaque microplate coated with antibodies, and the molecules in the serum specifically bound to the conjugate of horseradish peroxidase and the antibodies on the solid phase carrier. Separate and wash the unreacted free components. Then, luminol luminescence base solution is added, and the free energy released by the chemical reaction is used to excite the intermediate from the ground state to the excited state, and the energy is released in the form of photons. At this time, the microorifice plate is placed in the analyzer, and the photon number of each hole is read out by the photon counter through the three-dimensional transmission system inside the instrument. The molecular concentration in the sample was quantitatively analyzed according to the mathematical model established by the standard. Finally, print the data report.

\section{Follow-up}

After the end of CRT treatment, the patients were followed up using the Internet medical APP. All patients should go to the hospital for physical examination every 3 months and imaging examination every 6 months. If abnormalities are detected, determine whether further treatment is needed and, if so, give appropriate treatment according to treatment guidelines. All patients were followed for at least 3 years, or until death, disease progression, or study deadline (June 2020).

\section{Statistical analysis}

OPSCC patients were staged according to the 8th edition of the American Joint Committee on Cancer staging system (patients with unknown p16 status were classified as p16-negative). According to the disease stage, all patients were divided into the early group (stage I and II) and the advanced group (stage III and IV).

The study endpoints were (overall survival) OS and progression-free survival (PFS); The patient's death due to any cause is defined as OS, and the patient's local progression, distant metastasis, or death due to disease progression is defined as PFS.

Candidate variables include sex, age, smoking, alcohol consumption, primary tumor, disease stage, p16 status and comorbidity.

Cyfra21-1 is used as predictive variable, OS and PFS as outcome variable. Draw the receiver operating characteristic (ROC) curve, determine the optimal cutoff point based on the Youden index, and then convert Cyfra21-1 into a categorical variable. The survival of the patients was analyzed by Kaplan-Meier method, and the survival rate between groups was compared by the log-rank test. We used univariate and multivariate Cox proportional hazard models to analyze the impact indicators related to OS and PFS in patients, and to test the significance of Cyfra21-1 on the prognosis of patients. The double-tailed $p$ value of 0.05 was considered to be statistically significant. All statistical analyses were carried out using SPSS version 26.0 (IBM Corporation, Armonk, NY, USA).

\section{Results}

\section{Patient characteristics}

A total of 85 patients with OPSCC were included in this study. $12.9 \%$ of them were female, and $61.2 \%$ were $<60$ years old. Of the patients, $71.8 \%$ had smoked and $57.6 \%$ had drunk alcohol. Tonsil cancer (58.8\%), soft palate cancer $(22.4 \%)$ and root of tongue cancer $(18.8 \%)$ were identified by their anatomical sites. $16.5 \%$ of patients were in the early stage (stage I or II).Other systemic diseases were present in $40 \%$ of the participants. Among these patients, $22.4 \%$ of patients tested positive for $\mathrm{p} 16$, and $11.8 \%$ tested negative for p16; the p16 status of the remaining patients was unknown.

The best cutoff point for Cyfra21-1 was determined for both OS (Figure 1) and PFS (Figure 2) according to Youden's index (cutoff value $=2.93 \mathrm{ng} / \mathrm{mL}$ ). Transformation of Cyfra21-1 into a classification variable was then made 


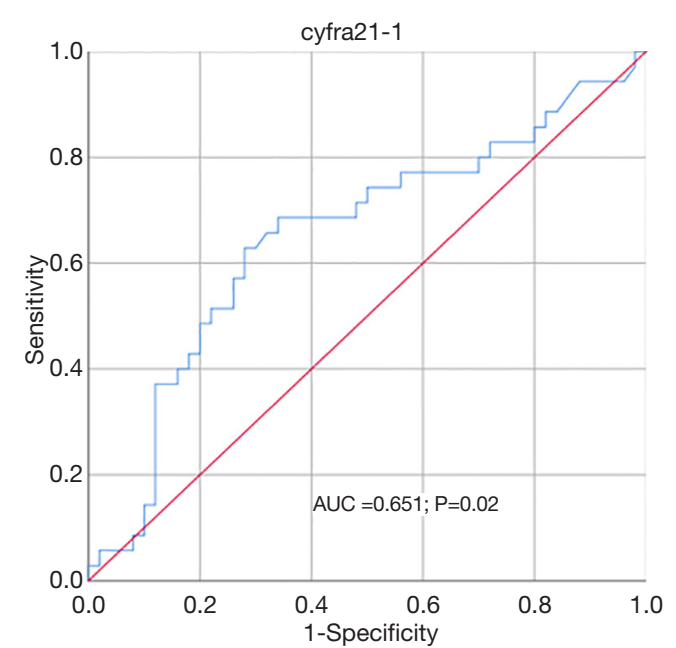

Figure 2 ROC curve for Cyfra21-1 predicting Cyfra21-1, cytokeratin 19 soluble fragment; PFS. ROC, receiver operating characteristic; PFS, progression-free survival.

according to this cutoff value ( $\leq 2.93, \mathrm{n}=50 ;>2.93, \mathrm{n}=35)$.

Table 1 shows the patients' baseline clinical characteristics according to Cyfra21-1. The baseline data of patients in different Cyfra21-1 groups were balanced and comparable, and there was no significant difference in clinical characteristics between the 2 groups.

\section{Survival analysis}

The median follow-up time was 37 months (interquartile interval: $19-74$ months). A total of 31 (36.5\%) patients died, and $35(41.2 \%)$ progressed. The 3 - and 5-year OS rates for the 85 patients with OPSCC were $62.9 \%$ and $46.9 \%$, respectively. The 3- and 5-year PFS rates were $54.9 \%$ and $48.0 \%$, respectively.

Kaplan-Meier curve analysis revealed that the OS of patients with high levels of Cyfra21-1 ( $\geq 2.93)$ was significantly shorter than that of patients with low Cyfra21-1 (<2.93) $(\log$-rank $\mathrm{P}<0.001)$ (Figure 3). The 3-year OS probability of patients in the low Cyfra21-1 group was $79.3 \%$, compared with $40 \%$ in the high Cyfra21-1 group. Also, patients with high Cyfra21-1 had significantly shorter PFS than patients with low Cyfra21-1 (log-rank $\mathrm{P}=0.001)$ (Figure 4). The 3 -year PFS rate was $69.0 \%$ and $35.1 \%$ in the low and high Cyfra21-1 groups, respectively.

Table 2 shows the significant correlation between OS $(\mathrm{P}<0.001)$, PFS $(\mathrm{P}=0.001)$, and Cyfra21-1. Sex, age, smoking status, alcohol consumption, primary tumor, disease
Table 1 Baseline clinical characteristics of the participants

\begin{tabular}{|c|c|c|c|c|}
\hline \multirow{2}{*}{ Characteristics } & \multirow{2}{*}{ Total, n (\%) } & \multicolumn{2}{|c|}{ Cyfra21-1 (ng/mL) } & \multirow{2}{*}{$P$ value } \\
\hline & & $\leq 2.93, \mathrm{n}(\%)$ & $>2.93, \mathrm{n}(\%)$ & \\
\hline Total & 85 & 50 & 35 & \\
\hline Sex & & & & 0.32 \\
\hline Male & $71(87.1)$ & $42(84.0)$ & $32(91.4)$ & \\
\hline Female & $11(12.9)$ & $8(16.0)$ & $3(8.6)$ & \\
\hline Age, years & & & & 0.05 \\
\hline$\leq 60$ & $52(61.2)$ & $35(70.0)$ & $17(48.6)$ & \\
\hline$>60$ & $33(38.8)$ & $15(30.0)$ & $18(51.4)$ & \\
\hline Smoking & & & & 0.13 \\
\hline Never & $24(28.2)$ & $11(22.0)$ & $13(37.1)$ & \\
\hline $\begin{array}{l}\text { Formerly or } \\
\text { currently }\end{array}$ & $61(71.8)$ & $39(18.0)$ & $22(62.9)$ & \\
\hline Alcohol consum & iption & & & 0.94 \\
\hline Never & $36(42.4)$ & $21(42.0)$ & $15(42.9)$ & \\
\hline $\begin{array}{l}\text { Formerly or } \\
\text { currently }\end{array}$ & $49(57.6)$ & $29(58.0)$ & $20(57.1)$ & \\
\hline Primary tumor & & & & 0.33 \\
\hline Tonsil & $50(58.8)$ & $28(56.0)$ & $22(62.9)$ & \\
\hline Soft palate & $19(22.4)$ & $10(20.0)$ & $9(25.7)$ & \\
\hline $\begin{array}{l}\text { Base of } \\
\text { tongue }\end{array}$ & $16(18.8)$ & $12(24.0)$ & $4(11.4)$ & \\
\hline Disease stage & & & & 0.10 \\
\hline $\mathrm{I} / \mathrm{II}$ & $14(16.5)$ & $11(22.0)$ & $3(8.6)$ & \\
\hline III/IV & $71(83.5)$ & $39(78.0)$ & $32(91.4)$ & \\
\hline p16 status & & & & 0.05 \\
\hline Positive & $19(22.4)$ & 7 (14.0) & $12(34.3)$ & \\
\hline Negative & $10(11.8)$ & $8(16.0)$ & $2(5.7)$ & \\
\hline Unknown & $56(65.9)$ & $35(70.0)$ & $21(60.0)$ & \\
\hline Comorbidity & & & & 0.07 \\
\hline No & $51(60.0)$ & $34(68.0)$ & $17(48.6)$ & \\
\hline Yes & $34(40.0)$ & $16(32.0)$ & $18(51.4)$ & \\
\hline
\end{tabular}

Cyfra21-1, cytokeratin 19 soluble fragment.

stage, p16 status, and comorbidity were not significantly correlated with OS and PFS.

Subsequently, the variables with $\mathrm{P}<0.1$ were included in multivariate analysis. Multivariate Cox proportional 


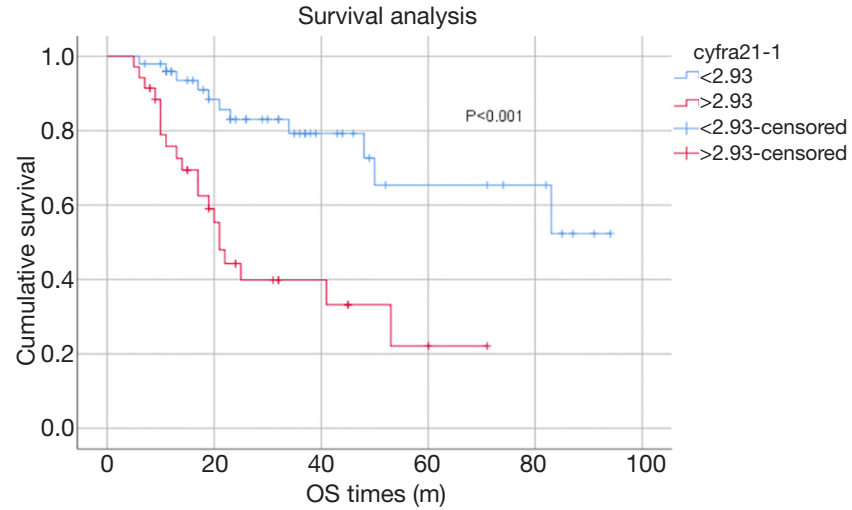

Figure 3 Kaplan-Meier curve of cumulative $\operatorname{Sin} 85$ patients with OPSCC treated with CRT according to Cyfra21-1 classification. Cyfra21-1, cytokeratin 19 soluble fragment; OS, overall survival; OPSCC, oropharyngeal squamous cell carcinoma; CRT, concurrent chemoradiotherapy.

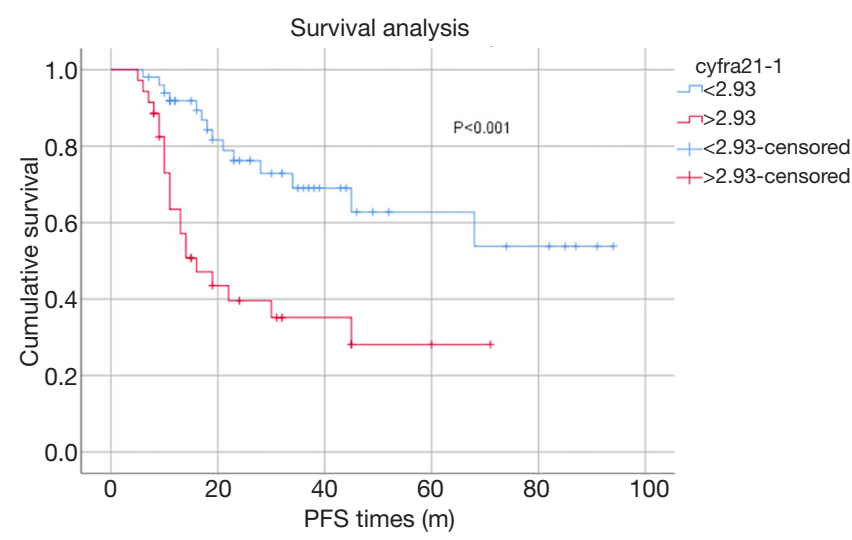

Figure 4 Kaplan-Meier curve of cumulative PFS in 85 patients with OPSCC treated with CRT according to Cyfra21-1 classification. Cyfra21-1, cytokeratin 19 soluble fragment; PFS, progression-free survival; OPSCC, oropharyngeal squamous cell carcinoma; CRT, concurrent chemoradiotherapy.

Table 2 Univariate Cox regression analysis for OS and PFS in patients with OPSCC treated with CRT

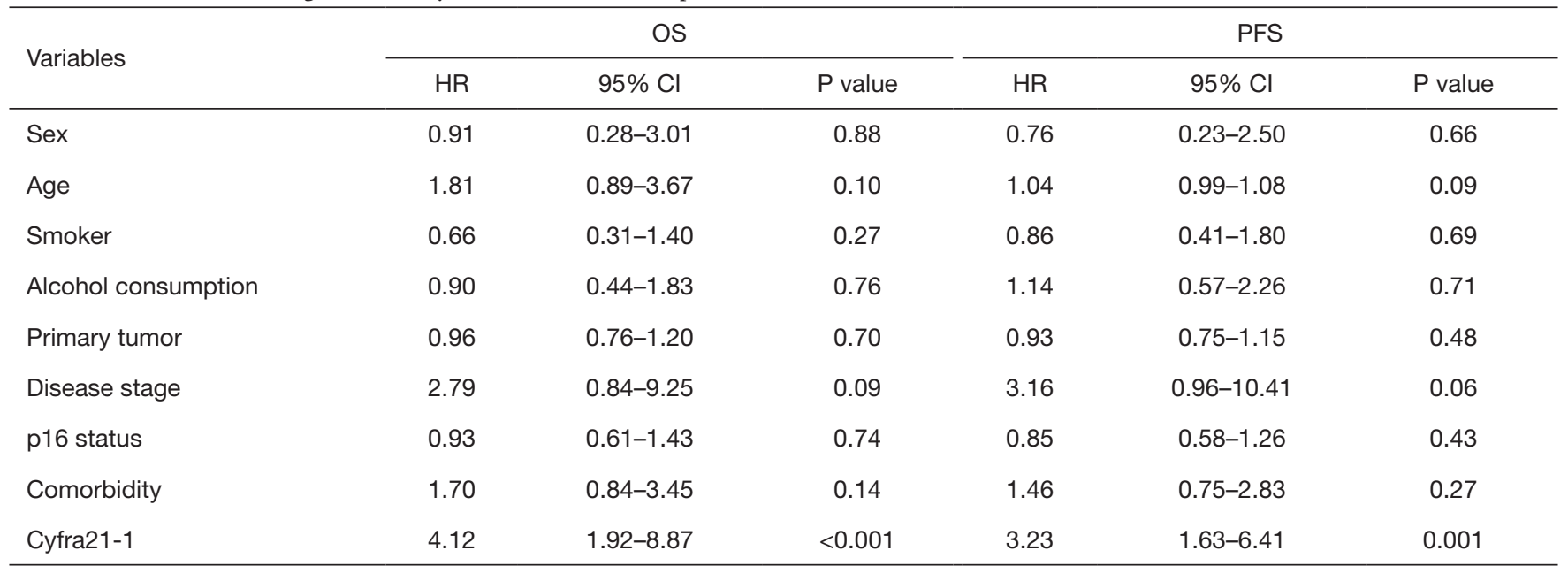

OS, overall survival; PFS, progression-free survival; OPSCC, oropharyngeal squamous cell carcinoma; CRT, concurrent chemoradiotherapy; Cyfra21-1, cytokeratin 19 soluble fragment.

hazard models were used to analyze the indicators that independently affect OS and PFS (Table 3). After adjusting for age and disease stage, multivariate analysis revealed that Cyfra21-1 Cyfra21-1 can independently affect the OS (HR $=3.57,95 \% \mathrm{CI}: 1.60-7.99, \mathrm{P}=0.002)$, and PFS (HR $=2.89,95 \%$ CI: $1.41-5.91, \mathrm{P}=0.004)$.

\section{Discussion}

In our study, we performed a retrospective analysis of clinical data from 85 patients with OPSCC to determine the prognostic significance of pre-treatment Cyfra21-1 in patients receiving CRT for OPSCC. We found that in OPSCC patients treated with CRT, pre-treatment Cyfra21-1 independently affected the patient's OS and PFS.

The main component of cell filaments is cytokeratin, and each epithelial cell is a differentiation dependent combination of two or more cytokerins. Cytokeratin 8, 18, and 19 are expressed in monolayers of the epithelium, including the bronchial epithelium, and in malignant 
Table 3 Multivariate Cox regression analysis for OS and PFS in patients with OPSCC treated with CRT

\begin{tabular}{|c|c|c|c|c|c|c|}
\hline Variables & \multicolumn{3}{|c|}{ OS } & \multicolumn{3}{|c|}{ PFS } \\
\hline Age & 1.34 & $0.63-2.83$ & 0.45 & 1.22 & $0.61-2.46$ & 0.58 \\
\hline Disease stage & 2.63 & $0.78-8.90$ & 0.12 & 2.94 & $0.87-9.93$ & 0.08 \\
\hline Cyfra21-1 & 3.57 & $1.60-7.99$ & 0.002 & 2.89 & $1.41-5.91$ & 0.004 \\
\hline
\end{tabular}

OS, overall survival; PFS, progression-free survival; OPSCC, oropharyngeal squamous cell carcinoma; CRT, concurrent chemoradiotherapy; Cyfra21-1, cytokeratin 19 soluble fragment.

tumors derived from these cells (17). After protein hydrolysis and degradation, insoluble cytokeratin filaments are released into the blood from dead or dying cells in the form of soluble fragments. Therefore, they can be used as serum tumor markers (18). The release of Cyfra21-1 has been closely related to apoptosis during tumor growth (19). The elevated level of serum Cyfra21-1 indicates that CK19 is degraded into soluble fragments in the blood, which increases the level of serum Cyfra21-1, and suggests the possibility of abnormal epithelial cells differentiating into cell carcinoma. The increase of Cyfra21-1 level is closely related to the metastatic site and histological grade of lung cancer. In lung cancer patients, Cyfra21-1 is an independent predictor of poor prognosis (20). High expression of Cyfra21-1 is an important factor affecting the survival of patients with advanced NSCLC (21). The preoperative serum Cyfra21-1 level was an independent predictor of lymph node metastasis in patients with esophageal squamous cancer (13). Rapid and quantitative detection of urinary Cyfra21-1 is a non-invasive approach for the diagnosis and prognosis of bladder cancer (14). In epithelial ovarian cancer, Cyfra21-1 was a poor prognostic factor associated with OS (15).

In several studies, Cyfra21-1 has very important clinical significance in the diagnosis and prognosis of patients with OPSCC. For instance, Rao et al. reported that increased serum Cyfra21-1 in patients with laryngeal cancer indicates increased likelihood of lymph node metastasis and recurrent metastasis (22). Furthermore, Song et al. revealed that serum Cyfra21-1 may be a reliable and effective biomarker for the detection and monitoring of nasopharyngeal carcinoma tumor progression $(23,24)$. Liu et al.'s study of a cohort of squamous cell lung carcinoma (SCLC) and OPSCC patients discovered that the detection of Cyfra21-1 is more sensitive to the recurrence of SCLC and OSCC, and can predict the recurrence of SCLC and OSCC in the early stage (25). Yuan et al.'s study suggested that the serum Cyfra21-1 level in early OPSCC patients was significantly higher than that in the benign tumor and healthy control groups. The serum Cyfra21-1 level in patients with advanced OPSCC was significantly higher than that in patients with early OPSCC, benign tumor patients, and healthy controls. The early diagnostic value of Cyfra21-1 for OPSCC is considerable (26). Liu et al. used ROC curves to calculate that the best cutoff is $2.365 \mathrm{ng} / \mathrm{mL}$, Yuan et al.'s cutoff was $2.17 \mathrm{ng} / \mathrm{mL}$; however, our study used ROC curves to calculate the Yoden index as the grouping basis of Cyfra21-1, and the cutoff was $2.93 \mathrm{ng} / \mathrm{mL}$, which was closer to the manufacturer's cutoff $(3.3 \mathrm{ng} / \mathrm{mL})$. Our current findings encourage us to pay more attention to OPSCC patients with high Cyfra21-1concentrations, as they are likely to require intensive treatment.

Our research had some limitations, including the retrospective nature of this study. A large number of patients may have been excluded due to incomplete clinical data, resulting in a certain degree of selection bias. In addition, our study did not consider any other factors that might potentially affect the expression of Cyfra21-1. In addition, the sample size we studied is not very large, which may be the reason why the area under the ROC curve is relatively small. In order to understand in more detail the guiding significance of Cyfra21-1 on the survival and progression of patients with OPSCC, we will design better prospective studies with sufficient sample size in the future.

\section{Conclusions}

Our results show that the increase of pre-treatment serum Cyfra21-1 was independently associated with the deterioration of OS and PFS in OPSCC patients treated with CRT. As an economical pre-treatment serum biomarker, pre-treatment Cyfra21-1 can be used as a prognostic marker for patients with OPSCC treated with CRT, which has important clinical significance. 


\section{Acknowledgments}

Funding: None.

\section{Footnote}

Reporting Checklist: The authors have completed the REMARK reporting checklist. Available at http://dx.doi. org/10.21037/atm-20-6124

Data Sharing Statement: Available at http://dx.doi. org/10.21037/atm-20-6124

Conflicts of Interest: All authors have completed the ICMJE uniform disclosure form (available at http://dx.doi. org/10.21037/atm-20-6124). The authors have no conflicts of interest to declare.

Ethical Statement: The authors are accountable for all aspects of the work in ensuring that questions related to the accuracy or integrity of any part of the work are appropriately investigated and resolved. All procedures performed in this study involving human participants were in accordance with the Declaration of Helsinki (as revised in 2013). The study was approved by the ethics committee of the Tianjin Medical University Cancer Institute and Hospital (No. bc2020110). A signed written informed consent agreement was provided by all patients before participation in the study.

Open Access Statement: This is an Open Access article distributed in accordance with the Creative Commons Attribution-NonCommercial-NoDerivs 4.0 International License (CC BY-NC-ND 4.0), which permits the noncommercial replication and distribution of the article with the strict proviso that no changes or edits are made and the original work is properly cited (including links to both the formal publication through the relevant DOI and the license). See: https://creativecommons.org/licenses/by-nc-nd/4.0/.

\section{References}

1. van der Waal I. Are we able to reduce the mortality and morbidity of oral cancer; some considerations. Med Oral Patol Oral Cir Bucal 2013;18:e33-7.

2. Kim K, Lee DJ. The updated AJCC/TNM staging system (8th edition) for oral tongue cancer. Transl Cancer Res 2019;8:S164-6.
3. Lee HJ, Kang YH, Lee JS, et al. Positive expression of NANOG, mutant p53, and CD44 is directly associated with clinicopathological features and poor prognosis of oral squamous cell carcinoma. BMC Oral Health 2015;15:153.

4. Sargeran K, Murtomaa H, Safavi S, et al. Survival after diagnosis of cancer of the oral cavity. Br J Oral Maxillofac Surg 2008;46:187-91.

5. Katz J, Jakymiw A, Ducksworth MK, et al. CIP2A expression and localization in oral carcinoma and dysplasia. Cancer Biol Ther 2010;10:694-9.

6. Lo Nigro C, Vivenza D, Denaro N, et al. DUSP2 methylation is a candidate biomarker of outcome in head and neck cancer. Ann Transl Med 2018;6:271.

7. Rai NP, Anekar J, Shivaraja Shankara YM, et al. Comparison of Serum Fucose Levels in Leukoplakia and Oral Cancer Patients. Asian Pac J Cancer Prev 2015;16:7497-500.

8. Nakata B, Chung Y, Kato Y, et al. Clinical significance of serum Cyfra21-1 in gastric cancer. Br J Cancer 1996;73:1529-32.

9. Fu L, Wang R, Yin L, et al. CYFRA21-1 tests in the diagnosis of non-small cell lung cancer: A meta-analysis. Int J Biol Markers 2019;34:251-61.

10. Zhao W, Liu Y, Kong F, et al. Correlations of pathological stage and prognosis of NSCLC patients with changes in serum CEA and CYFRA21-1 and CT characteristics. Panminerva Med 2020;62:67-9.

11. Liu X, Zhao H, Mu L. Serum expression of NSE, ProGrp and Cyfra21-1 in patients with small cell lung cancer and prognosis. Int J Clin Exp Med 2020;13:3384-92.

12. Li B, Yuan Q, Zou Y'T, et al. CA-125, CA-153, and CYFRA21-1 as clinical indicators in male lung cancer with ocular metastasis. J Cancer 2020;11:2730-6.

13. Mei X, Zhu X, Zuo L, et al. Predictive significance of CYFRA21-1, squamous cell carcinoma antigen and carcinoembryonic antigen for lymph node metastasis in patients with esophageal squamous cancer. Int J Biol Markers 2019;34:200-4.

14. Lei Q, Zhao L, Ye S, et al. Rapid and quantitative detection of urinary Cyfra21-1 using fluorescent nanosphere-based immunochromatographic test strip for diagnosis and prognostic monitoring of bladder cancer. Artif Cells Nanomed Biotechnol 2019;47:4266-72.

15. Jin C, Yang M, Han X, et al. Evaluation of the value of preoperative CYFRA21-1 in the diagnosis and prognosis of epithelial ovarian cancer in conjunction with CA125.J Ovarian Res 2019;12:114.

16. He G, Liao Y, Li M, et al. The diagnostic efficacy of 
CYFRA21-1 on intrahepatic cholangiocarcinoma: A metaanalysis. Clin Res Hepatol Gastroenterol 2019;43:266-72.

17. Viac J, Reano A, Brochier J, et al. Reactivity pattern of a monoclonal antikeratin antibody (KL1). J Invest Dermatol 1983;81:351-4.

18. Nisman B, Lafair J, Heching N, et al. Evaluation of tissue polypeptide specific antigen, Cyfra21-1, and carcinoembryonic antigen in nonsmall cell lung carcinoma: does the combined use of cytokeratin markers give any additional information? Cancer 1998;82:1850-9.

19. Sheard MA, Vojtesek B, Simickova M, et al. Release of cytokeratin-18 and -19 fragments (TPS and Cyfra21-1) into the extracellular space during apoptosis. J Cell Biochem 2002;85:670-7.

20. Zhang L, Liu D, Li L, et al. The important role of circulating CYFRA21-1 in metastasis diagnosis and prognostic value compared with carcinoembryonic antigen and neuron-specific enolase in lung cancer patients. BMC Cancer 2017;17:96.

21. Ren H, Hu Y, Xie T, et al. Effect of gefitinib on serum EGFR and CYFRA21-1 in patients with advanced nonsmall cell lung cancer. Oncol Lett 2019;18:4167-75.

Cite this article as: $\mathrm{Li} \mathrm{L}$, Liu G, Jin K, Lu H, Zhai X, Zhou M, Yue K, Duan Y, Wu Y, Wang X. Prognostic significance of pre-treatment serum Cyfra21-1 as a tumor marker in patients with oropharyngeal squamous cell carcinoma treated with concurrent chemoradiotherapy. Ann Transl Med 2020;8(20):1302. doi: 10.21037/atm-20-6124
22. Rao LH, Zhang L, Tian L, et al. The clinical signifinace of CEA, Cyfra21-1 and SCC in laryngeal carcinoma's clinicopathological parameters. Lin Chung Er Bi Yan Hou Tou Jing Wai Ke Za Zhi 2017;31:1182-6.

23. Song XM, Wang ZJ, Cao WJ, et al. The value of circulating CYFRA21-1 expression in patients with nasopharyngeal carcinoma: a study of 529 subjects. Int J Clin Oncol 2016;21:1038-45.

24. Song XM, Wang SZ, Wang ZJ, et al. Serum CYFRA21-1 as an effective tumor biomarker for patients with nasopharyngeal carcinoma. Neoplasma 2015;62:124-9.

25. Liu L, Liu B, Zhu LL, et al. CYFRA21-1 as a serum tumor marker for follow-up patients with squamous cell lung carcinoma and oropharynx squamous cell carcinoma. Biomark Med 2013;7:591-9.

26. Yuan C, Yang K, Tang H, et al. Diagnostic values of serum tumor markers Cyfra21-1, SCCAg, ferritin, CEA, CA19-9, and AFP in oral/oropharyngeal squamous cell carcinoma. Onco Targets Ther 2016;9:3381-6.

(English Language Editor: J. Jones) 